\title{
Non-small-cell lung cancer involving the pleura: a narrative review on the diagnostic and therapeutic pathway
}

\author{
Alessandro Gonfiotti, Lavinia Gatteschi, Alberto Salvicchi, Luca Voltolini \\ Thoracic Surgery, Cardiothoracic Department, University of Florence, Florence, Italy \\ Contributions: (I) Conception and design: All authors; (II) Administrative support: A Gonfiotti, L Voltolini; (III) Provision of study materials: L \\ Gatteschi, A Salvicchi; (IV) Collection and assembly of data: A Gonfiotti, L Gatteschi, A Salvicchi; (V) Data analysis and interpretation: L Gatteschi, \\ A Salvicchi; (VI) Manuscript writing: All authors; (VII) Final approval of manuscript: All authors. \\ Correspondence to: Lavinia Gatteschi, MD. Thoracic Surgery Unit, University Hospital Careggi, Largo Brambilla, 1, 50134 Florence, Italy. \\ Email: laviniagatteschi@gmail.com.
}

\begin{abstract}
Visceral pleural invasion (VPI) is considered a challenging topic in the management of patients with non-small-cell lung cancer (NSCLC) since it has been incorporated into the last edition of tumor, node, metastasis (TNM) staging as a size independent T2 factor. VPI presents adverse outcomes and poorer prognosis, with higher rate of mediastinal lymph node metastases and malignant pleural effusion. In literature few studies investigated it, therefore there is still debate on the global management of these patients, from the preoperative staging to the optimal surgical procedure and the postoperative follow-up or the need of adjuvant chemotherapy. Our work is a narrative review taking into consideration the most recent and relevant articles concerning VPI and NSCLC. We have summarized the most appropriate diagnostic pathway, surgical approach and post-operative management in order to give these patients the best therapeutic option. The preoperatively prediction of pleural invasion is still too weak to ensure a preoperative upstaging. On the other hand, lobectomy with adequate lymph node dissection seems to be the most appropriate therapeutic option in these patients. Furthermore, there is no evidence of the usefulness of adjuvant chemotherapy and the lack of clinical trials leads clinicians to evaluate case-by-case the global management of these patients.
\end{abstract}

Keywords: Visceral pleural invasion (VPI); non-small-cell lung cancer (NSCLC); early stage lung cancer; locally advanced lung cancer

Received: 27 May 2020; Accepted: 03 November 2020; Published: 25 May 2022.

doi: $10.21037 /$ ccts-20-108

View this article at: http://dx.doi.org/10.21037/ccts-20-108

\section{Introduction}

Visceral pleural invasion (VPI) has been reported as a prognostic value in non-small-cell lung cancer (NSCLC) for the first time in 1958 by Brewer et al. (1). In 1997 it was incorporated as a negative prognosticator within the fifth edition of tumor, node, metastasis (TNM) staging criteria (2) and the seventh and eight editions of TNM staging system introduced VPI as a size independent T2 factor, upstaging tumors $\leq 3 \mathrm{~cm}$ to T2a.

A lung cancer is classified as PL1 when it invades beyond the elastic layer of the visceral pleura, as PL2 when it extends to the visceral pleural surface and as PL3 when it invades any component of the parietal pleura $(3,4)$.

During the past several decades literature has widely demonstrated that patients with VPI have worse outcomes and poorer survival, with higher frequency of pleural effusion, lymph node metastasis and postoperative recurrence $(5,6)$. There is still controversy in the global management of these patients, from the preoperative staging to the optimal surgical procedure and the postoperative follow-up or the need of adjuvant chemotherapy.

The aim of this study is to review the current literature on the overall management, the preoperative diagnosis and the most appropriate therapeutic options of patients with NSCLC and VPI. We present the following review 
Table 1 Preoperatively predicted pleural invasion, results of studies

\begin{tabular}{|c|c|c|c|c|}
\hline Study, year & Report & Population & Topics investigated & Findings \\
\hline $\begin{array}{l}\text { Bai et al. (9), } \\
2019\end{array}$ & Review & $\begin{array}{l}\text { Not } \\
\text { specified }\end{array}$ & CT, PET & CT best predicts VPI \\
\hline $\begin{array}{l}\text { Hsu et al. (10), } \\
2016\end{array}$ & $\begin{array}{l}\text { Original } \\
\text { report }\end{array}$ & $\begin{array}{c}141 \\
\text { patients }\end{array}$ & 3 types of pleural tags (type 1,2 and 3) & $\begin{array}{l}\text { Type } 2 \text { relate to VPI: sensitivity } 36.4 \% \text {, } \\
\text { specificity } 92.8 \% \text {, accuracy } 71 \%\end{array}$ \\
\hline $\begin{array}{l}\text { Yang et al. (11), } \\
2018\end{array}$ & $\begin{array}{l}\text { Original } \\
\text { report }\end{array}$ & $\begin{array}{c}52 \\
\text { patients }\end{array}$ & $\begin{array}{l}5 \text { types of non-interlobar fissure pleura (Group A), } \\
4 \text { types of interlobar fissure pleura (Group B), pleural } \\
\text { indentation fraction }\end{array}$ & $\begin{array}{l}\text { Type III-IV of Group A and type I and III of } \\
\text { Group B indicate VPI }\end{array}$ \\
\hline $\begin{array}{l}\text { Kim et al. (14), } \\
2019\end{array}$ & $\begin{array}{l}\text { Original } \\
\text { report }\end{array}$ & $\begin{array}{c}695 \\
\text { patients }\end{array}$ & $\begin{array}{l}\text { Pleural retraction, pleural tags; tumor contact length } \\
\text { with the pleura }\end{array}$ & Accuracy to predict VPI: $62.7-72.3 \%$ \\
\hline $\begin{array}{l}\text { lizuka et al. (15), } \\
2019\end{array}$ & $\begin{array}{l}\text { Original } \\
\text { report }\end{array}$ & $\begin{array}{c}376 \\
\text { patients }\end{array}$ & $\begin{array}{l}\text { Tumor size, tumor contact length with pleura, clinical } \\
\mathrm{N}+\text {, smoking index, carcinoembryonic antigen level }\end{array}$ & Score $\geq 8$ can predict VPI in $64 \%$ of patients \\
\hline
\end{tabular}

CT, computed tomography; VPI, visceral pleural invasion; PET, positron emission tomography; OR, odds ratio.

in accordance with the Narrative Review reporting checklist (available at https://ccts.amegroups.com/article/ view/10.21037/ccts-20-108/rc).

\section{Methods}

This paper was performed by inserting on PubMed platform the following keywords in the search field: "visceral pleural invasion lung cancer"; "nsclc involving the pleura" and "early-stage NSCLC treatment". The review was drafted including only the articles written in English. From 1990 to 2020, the authors have found and screened 349 articles focusing on the year of publication and the topics investigated (preoperative, surgical and postoperative management). No limits have been set on studies design, no formal statistical procedure was performed. Twenty-four studies were included for final review: 9 focusing on the preoperative prediction of VPI, 6 on the most appropriate surgical approach and lymph nodes dissection and 9 on the post-operative management.

\section{Discussion}

In order to clarify the current situation of the scientific literature on this topic, we decided to divide this review into three sections, each of them focusing on one of the three steps of NSCLC management: the diagnostic phase, the surgical approach and postoperative treatment.

\section{The diagnostic phase: is VPI predictable preoperatively?}

Since VPI is considered an adverse factor for NSCLC, numerous studies have investigated whether it is possible to predict preoperatively pleural invasion by computed tomography (CT) and positron emission tomography (PET) findings (Table 1).

Most of the studies focused the attention on the characteristics of the lesion on the CT and the presence or absence of pleural tags, which are defined as linear strands linking the nodule to the pleural surface (7-9).

In their retrospective investigation on 141 patients with NSCLC, Hsu and colleagues correlated VPI to type 2 
pleural tags (showing soft tissue component at the pleural edge on mediastinal window images) with $92.8 \%$ specificity and $36.4 \%$ sensitivity (10).

Another retrospective study by Yang et al. reported that one or more pleural tags, as well as a tumor pushing the pleura, were associated with VPI in 52 adenocarcinomas of the lung (11).

Focusing on the radiological shape of the pulmonary nodules, Zhao et al. showed that VPI appeared most frequently in part solid nodules than in the pure ground glass ones, with an incidence of $32.2 \%$ vs. 17.4\% (12).

Part solid nodules with a solid component proportion greater than $50 \%$, combined with pleural thickening, has been defined as a significant indicator of VPI by Ahn and colleagues too, with a specificity of $99.2 \%$ (13).

On the other hand, Kim et al. wanted to validate the diagnostic accuracy of CT findings for the prediction of VPI in patients with lung adenocarcinoma, but they actually showed that staging with the CT signs of VPI would falsely upstage up to $50 \%$ of patients from T1 to T2 (14). Based on their study population CT features of VPI have an accuracy of $62.7-72.3 \%$ and were not independent prognostic factors for disease-free survival (DFS) in clinical T1 lung adenocarcinomas.

Furthermore, Iizuka and colleagues defined a risk scoring system in order to predict VPI from CT findings (i.e., tumor diameter, length of the contact between the tumor and the pleura, whether the lesion was adjacent to a cavitary lesion or it was a contractile lesion) and clinicopathological factors, such as smoking index, serum carcinoembryonic antigen (CEA) level and the presence of clinical lymph node metastasis (15). They retrospectively examined 376 cases of surgically treated NSCLC in which tumor was $\leq 7 \mathrm{~cm}$ in diameter and in contact with the pleura on the preoperative CT scan and their findings displayed that $64 \%$ of the cases with a score $\geq 8$ (cut off value) had pathological VPI.

Preoperative CT findings are likely to correlate to pathological VPI, though currently there is still not enough evidence to use these CT features in a staging system.

We hope that in the future, combining the best technologies and the results of the studies that will be conducted, we will be able to predict the presence of VPI, in order to target these patients to the most adequate oncological treatment.

\section{Surgical approach}

Lung cancer is the major cause of death from cancer- related worldwide. Various histopathological forms of lung cancer are recognized and approximately $85 \%$ of patients are affected by NSCLC. Surgical resection for early stage NSCLC is considered the first-choice therapeutic option for eligible candidates and it involves performing a lobectomy or greater resection procedures (16).

However, sub-lobar resections, intended both as wedge resections and segmentectomies, represent a surgical alternative in elderly patients with significant comorbidities and poor functional respiratory reserve.

According to the National Comprehensive Cancer Network (NCCN) Clinical Practice Guideline in Oncology for NSCLC, a sub-lobar resection can be performed in patients with a tumor size $\leq 2 \mathrm{~cm}$ combined with adenocarcinoma in situ (AIS) histology, $\geq 50 \%$ groundglass appearance on CT or a long doubling radiologic surveillance time ( $\geq 400$ days) (17).

Despite VPI is considered an adverse and aggressive prognostic factor in patients with surgically resected NSCLC, literature is still poor on the optimal surgical strategy for early-stage NSCLC presenting VPI and the topic remains controversial and unclear.

Xie $e t a l$. have reported that sub-lobar resection was an independent risk factor for recurrence in patients with lung adenocarcinomas $2 \mathrm{~cm}$ or less with surgical presence of VPI; in case of VPI a lobectomy with lymphadenectomy should be performed (18).

In line with these findings, in a recent study Wo and colleagues concluded that patients with early stage NSCLC (stage IA and IB) who underwent sub-lobar resection had a worse survival than those who underwent lobectomy (19).

On the other hand, Moon et al. conducted a retrospective study on 271 patients (stage I NSCLC $\leq 2 \mathrm{~cm}$ ) undergoing surgical resection and reported that sub-lobar resection was not a risk factor for disease relapse. Survival rates for patients with small-size $(\leq 2 \mathrm{~cm})$ NSCLC and visceral pleural or lymphovascular invasion did not differ based on the surgical technique used, therefore lobectomy could be avoided (20).

In their retrospective cohort study Subramanian et al. focused on patients with early-stage NSCLC who underwent either lobectomy or sub-lobar resection (segmentectomy or wedge resection). They found that overall survival (OS) was similar, however patients undergoing lobectomy had lower locoregional recurrence. Therefore, the authors concluded that lobectomy represents the first choice surgery in patients with T1 N0 tumors (21).

Yu et al. analyzed a cohort of 1,386 patients with NSCLC 
less than $2 \mathrm{~cm}$ in size and VPI; the analysis shows that patients treated with lobectomy had better OS and DFS than those who underwent sublobectomy (17).

Several studies have shown the ability of VPI to cause malignant pleural effusions and higher mediastinal lymph node metastases, therefore surgical resection should also include extensive lymph node dissection in order to obtain better staging. Moreover, disease relapse is directly related to the presence of metastatic lymph nodes resulting in an unfavorable prognosis.

Liang et al. have evaluated the ratio of metastatic nodes to the total number of examined lymph nodes and, during dissection, they recommend taking a minimum of 16 lymph nodes for optimal staging and better long-term survival, since an extensive lymph nodes examination is also associated with a more accurate staging and therefore a better postoperative management (22).

Wo et al. showed that patients with VPI need more lymph nodes dissection (14-16 LNs) than non-VPI patients (7-8 LNs). In the suspicion of VPI the surgeon should perform an extended lymphadenectomy to increase the survival benefit (19).

A less extensive lymph node dissection reduces the probability of identifying metastatic lymph node regions leading to under staging.

In conclusion, although few scientific papers in the literature, patients with NSCLC $\leq 2 \mathrm{~cm}$ and VPI should undergo surgical resection by lobectomy. In general, lobectomy guarantees greater resection margins compared to sublobectomy and it demonstrated a higher survival rate (OS and DFS). In addition, in these patients it is necessary to perform an adequate lymph node dissection both to discover any lymph node metastases and to improve their prognosis.

\section{Postoperative management}

Stages IA and IB of NSCLC have a good prognosis with a five years OS of $82 \%$ and $66 \%$ respectively, therefore surgery is the optimal strategy for patients with early-stage.

However, several factors have been related to a poorer prognosis in these patients with early stage lung cancer, such as sex, age, smoking, tumor size, VPI and lymphovascular invasion (23).

Regarding VPI, the higher frequency of lymph node metastasis and malignant pleural effusion is probably due to the anatomy of the visceral pleura itself, in fact it contains a rich lymphatic network between the elastic layers which could drain the closest cancer cells into the mediastinal lymph nodes.

Many studies have tried to define whether the poorer prognosis of patients presenting VPI depends on tumor size and/or nodes positivity and if it may be improved by adjuvant chemotherapy, along with the surgical techniques already reviewed.

In literature important trials have reached controversial resulted: the ANITA trial, for example, revealed that adjuvant chemotherapy resulted in improved OS. On the other hand, the CALBG 9633 trial, which focused on patients with stage IB disease didn't show any benefits on OS with adjuvant chemotherapy $(24,25)$.

To date, there are no precise indications on the real benefit of adjuvant therapy in these patients, the possibility to perform it is still widely debated and solid studies are lacking.

The systematic review and meta-analysis conducted by Jiang and colleagues demonstrated that VPI influences 5 years OS, regardless of tumor size, even if the OR resulted as higher in tumor less than $3 \mathrm{~cm}$. Thus, they suggested that patients with NSCLC stage IB and larger tumors with VPI might be considered for adjuvant chemotherapy after surgical resection (26).

The same suggestion came from Huang et al., who conducted a meta-analysis to show that VPI was actually associated with higher risk of recurrence and death and it was a size independent poor prognostic factor in patients with NSCLC stage I (27).

Yang et al. used a propensity score matching to report that tumors between 1 and $3 \mathrm{~cm}$ presenting VPI have a significantly worse prognosis than tumors not presenting it, while with increasing tumor size and nodal staging, VPI seems not to affect the prognosis anymore (28).

On the contrary, Park and colleagues showed that, while VPI is confirmed as a significant risk factor for prognosis, it shouldn't be considered as a decisive factor for adjuvant chemotherapy, which in their study didn't affect the prognosis of stage IB NSCLC (29).

Consistent with these findings, Wang et al. retrospectively analyzed 569 patients who underwent pulmonary resection to conclude that platinum-based adjuvant chemotherapy resulted in a worse five years OS than observation alone for patients with stage IB NSCLC (30).

Recently, Qian and colleagues tried to establish a recurrence risk-scoring model for patients with surgically resected lung adenocarcinoma in order to find suitable candidates for adjuvant chemotherapy. They conclude 
a nomogram predicting individual recurrence-free survival, which indicates that high risk patients with stage I adenocarcinoma may benefit from adjuvant chemotherapy (31).

There are still not enough clinical trials on carrying out the need of adjuvant chemotherapy on stage IB NSCLC and results are often contradictory. However, there is some evidence from literature review that shows how patients with early stage NSCLC, VPI and lymphovascular invasion could benefit from post-intervention chemotherapy. Although further studies are needed to confirm or disconfirm the usefulness of adjuvant therapy in early stage NSCLC (IA-IB), individual and case-bycase consideration should be given to the possibility of chemotherapy after surgical resection in highly selected patients.

\section{Summary}

VPI is worldwide recognized as a size-independent aggressive prognostic factor in early stage NSCLC. Patients presenting it have worse outcomes and poorer prognosis, with higher rate of mediastinal lymph node metastases and malignant pleural effusion. Although, there is still debate in literature on the correct pathway to address these patients to.

The existing imaging techniques, especially CT, could predict with a reasonable approximation the presence of VPI, but there are still not enough solid signs nor scoring systems to ensure a preoperative upstaging.

Furthermore, the optimal surgical strategy for earlystage NSCLC presenting VPI seems to be more delineated. In fact, although literature is still poor in targeted studies, most published papers agree on the surgical need for lobectomy and extensive lymph nodes dissection.

In the end, the lack of clinical trials on the postoperative management of these patients leads clinicians to evaluate case-by-case the possibility to perform adjuvant chemotherapy in highly selected subjects.

\section{Acknowledgments}

Funding: None.

\section{Footnote}

Provenance and Peer Review: This article was commissioned by the Guest Editors (Davide Tosi and Alessandro Palleschi) for the series "The Treatment of Locally Advanced Lung
Cancer" published in Current Challenges in Thoracic Surgery. The article has undergone external peer review.

Reporting Checklist: The authors have completed the Narrative Review reporting checklist. Available at https:// ccts.amegroups.com/article/view/10.21037/ccts-20-108/rc

Conflicts of Interest: All authors have completed the ICMJE uniform disclosure form (available at https://ccts.amegroups. com/article/view/10.21037/ccts-20-108/coif). The series "The Treatment of Locally Advanced Lung Cancer" was commissioned by the editorial office without any funding or sponsorship. The authors have no other conflicts of interest to declare.

Ethical Statement: The authors are accountable for all aspects of this work in ensuring that questions related to the accuracy or integrity of any part of this work are appropriately investigated and resolved.

Open Access Statement: This is an Open Access article distributed in accordance with the Creative Commons Attribution-NonCommercial-NoDerivs 4.0 International License (CC BY-NC-ND 4.0), which permits the noncommercial replication and distribution of the article with the strict proviso that no changes or edits are made and the original work is properly cited (including links to both the formal publication through the relevant DOI and the license). See: https://creativecommons.org/licenses/by-nc-nd/4.0/.

\section{References}

1. Brewer LA, Bai AF, Little JN, et al. Carcinoma of the lung; practical classification for early diagnosis and surgical treatment. J Am Med Assoc 1958;166:1149-55.

2. Mountain CF. Revisions in the international system for staging lung cancer. Chest 1997;111:1710-7.

3. Goldstraw P, Chansky K, Crowley J, et al. The IASLC lung cancer staging project: proposals for revision of the TNM stage groupings in the forthcoming (eighth) edition of the TNM classification for lung cancer. J Thorac Oncol 2016;11:39-51.

4. Travis WD, Brambilla E, Rami-Porta R, et al. Visceral pleural invasion: pathologic criteria and use of elastic stains: proposal for the 7th edition of the TNM classification for lung cancer. J Thorac Oncol 2008;3:1384-90.

5. Deng HY, Li G, Luo J, et al. Novel biologic factors 
correlated to visceral pleural invasion in early-stage non-small cell lung cancer less than $3 \mathrm{~cm}$. J Thorac Dis 2018;10:2357-64.

6. Shimizu K, Yoshida J, Nagai K, et al. Visceral pleural invasion is an invasive and aggressive indicator of nonsmall cell lung cancer. J Thorac Cardiovasc Surg 2005;130:160-5.

7. Ebara K, Takashima S, Jiang B, et al. Pleural invasion by peripheral lung cancer: prediction with three-dimensional CT. Acad Radiol 2015;22:310-9.

8. Kuriyama K, Tateishi R, Kumatani T, et al. Pleural invasion by peripheral bronchogenic carcinoma: assessment with three-dimensional helical CT. Radiology 1994;191:365-9.

9. Bai JH, Hsieh MS, Liao HC, et al. Prediction of pleural invasion using different imaging tools in non-small cell lung cancer. Ann Transl Med 2019;7:33.

10. Hsu JS, Han IT, Tsai TH, et al. Pleural Tags on CT Scans to Predict Visceral Pleural Invasion of Non-Small Cell Lung Cancer That Does Not Abut the Pleura. Radiology 2016;279:590-6.

11. Yang S, Yang L, Teng L, et al. Visceral pleural invasion by pulmonary adenocarcinoma $\leq 3 \mathrm{~cm}$ : the pathological correlation with pleural signs on computed tomography. J Thorac Dis 2018;10:3992-9.

12. Zhao LL, Xie HK, Zhang LP, et al. Visceral pleural invasion in lung adenocarcinoma $\leq 3 \mathrm{~cm}$ with ground-glass opacity: a clinical, pathological and radiological study. J Thorac Dis 2016;8:1788-97.

13. Ahn SY, Park CM, Jeon YK, et al. Predictive CT Features of Visceral Pleural Invasion by T1-Sized Peripheral Pulmonary Adenocarcinomas Manifesting as Subsolid Nodules. AJR Am J Roentgenol 2017;209:561-6.

14. Kim H, Goo JM, Kim YT, et al. CT-defined Visceral Pleural Invasion in T1 Lung Adenocarcinoma: Lack of Relationship to Disease-Free Survival. Radiology 2019;292:741-9.

15. Iizuka S, Kawase A, Oiwa $\mathrm{H}$, et al. A risk scoring system for predicting visceral pleural invasion in non-small lung cancer patients. Gen Thorac Cardiovasc Surg 2019;67:876-9.

16. Howington JA, Blum MG, Chang AC, et al. Treatment of stage I and II non-small cell lung cancer: Diagnosis and management of lung cancer, 3rd ed: American College of Chest Physicians evidence-based clinical practice guidelines. Chest 2013;143:e278S-313S.

17. Yu Y, Huang R, Wang $\mathrm{P}$, et al. Sublobectomy versus lobectomy for long-term survival outcomes of early- stage non-small cell lung cancer with a tumor size $\leq 2$ $\mathrm{cm}$ accompanied by visceral pleural invasion: a SEER population-based study. J Thorac Dis 2020;12:592-604.

18. Xie H, Su H, Chen D, et al. Use of Autofluorescence to Intraoperatively Diagnose Visceral Pleural Invasion From Frozen Sections in Patients With Lung Adenocarcinoma 2 Cm or Less. Am J Clin Pathol 2019;152:608.

19. Wo Y, Zhao Y, Qiu T, et al. Impact of visceral pleural invasion on the association of extent of lymphadenectomy and survival in stage I non-small cell lung cancer. Cancer Med 2019;8:669-78.

20. Moon Y, Lee KY, Park JK. Prognosis After Sublobar Resection of Small-sized Non-small Cell Lung Cancer with Visceral Pleural or Lymphovascular Invasion. World J Surg 2017;41:2769-77.

21. Subramanian M, McMurry T, Meyers BF, et al. LongTerm Results for Clinical Stage IA Lung Cancer: Comparing Lobectomy and Sublobar Resection. Ann Thorac Surg 2018;106:375-81.

22. Liang W, He J, Shen Y, et al. Impact of Examined Lymph Node Count on Precise Staging and Long-Term Survival of Resected Non-Small-Cell Lung Cancer: A Population Study of the US SEER Database and a Chinese MultiInstitutional Registry. J Clin Oncol 2017;35:1162-70.

23. Wang S, Xu J, Wang R, et al. Adjuvant chemotherapy may improve prognosis after resection of stage I lung cancer with lymphovascular invasion. J Thorac Cardiovasc Surg 2018;156:2006-2015.e2.

24. Douillard JY, Rosell R, De Lena M, et al. Adjuvant vinorelbine plus cisplatin versus observation in patients with completely resected stage IB-IIIA non-small-cell lung cancer (Adjuvant Navelbine International Trialist Association [ANITA]): a randomised controlled trial. Lancet Oncol 2006;7:719-27.

25. Strauss GM, Herndon JE 2nd, Maddaus MA, et al. Adjuvant paclitaxel plus carboplatin compared with observation in stage IB non-small-cell lung cancer: CALGB 9633 with the Cancer and Leukemia Group B, Radiation Therapy Oncology Group, and North Central Cancer Treatment Group Study Groups. J Clin Oncol 2008;26:5043-51.

26. Jiang L, Liang W, Shen J, et al. The Impact of Visceral Pleural Invasion in Node-Negative Non-small Cell Lung Cancer A Systematic Review and Meta-analysis. Chest 2015;148:903-11.

27. Huang H, Wang T, Hu B, et al. Visceral Pleural Invasion Remains a Size-Independent Prognostic Factor in Stage I Non-Small Cell Lung Cancer. Ann Thorac Surg 
2015;99:1130-9.

28. Yang X, Sun F, Chen L, et al. Prognostic value of visceral pleural invasion in non-small cell lung cancer: A propensity score matching study based on the SEER registry. J Surg Oncol 2017;116:398-406.

29. Park HJ, Park HS, Cha YJ, et al. Efficacy of adjuvant chemotherapy for completely resected stage IB nonsmall cell lung cancer: a retrospective study. J Thorac Dis 2018;10:2279-87.

doi: $10.21037 /$ ccts-20-108

Cite this article as: Gonfiotti A, Gatteschi L, Salvicchi A, Voltolini L. Non-small-cell lung cancer involving the pleura: a narrative review on the diagnostic and therapeutic pathway. Curr Chall Thorac Surg 2022;4:20.
30. Wang J, Wu N, Lv C, et al. Should patients with stage IB non-small cell lung cancer receive adjuvant chemotherapy? A comparison of survival between the 8 th and 7 th editions of the AJCC TNM staging system for stage IB patients. J Cancer Res Clin Oncol 2019;145:463-9.

31. Qian J, Xu J, Wang S, et al. Adjuvant Chemotherapy Candidates in Stage I Lung Adenocarcinomas Following Complete Lobectomy Ann Surg Oncol 2019;26:2392-400. 